\title{
The associative and limbic thalamus in the pathophysiology of obsessive-compulsive disorder: an experimental study in the monkey
}

\author{
JY Rotge ${ }^{1,2,5}$, B Aouizerate ${ }^{1,2,5}$, V Amestoy ${ }^{1}$, V Lambrecq ${ }^{1,3}$, N Langbour ${ }^{1}$, TH Nguyen $^{1}$, S Dovero ${ }^{1}$, L Cardoit ${ }^{4}$, J Tignol ${ }^{2}$, B Bioulac ${ }^{1,3}$, \\ P Burbaud ${ }^{1,3}$ and D Guehl ${ }^{1,3}$
}

Obsessive-compulsive disorder (OCD) is a frequent psychiatric disorder characterized by repetitive intrusive thoughts and severe anxiety, leading to compulsive behaviors. Although medical treatment is effective in most cases, resistance is observed in about $30 \%$ of patients. In this context, deep brain stimulation (DBS) of the caudate or subthalamic nuclei has been recently proposed with encouraging results. However, some patients were unimproved or exhibited awkward side effects. Therefore, exploration of new targets for DBS remains critical in OCD. In the latter, functional imaging studies revealed overactivity in the limbic and associative cortico-subcortical loops encompassing the thalamus. However, the role of the thalamus in the genesis of repetitive behaviors and related anxiety is unknown. Here, we tested the hypothesis that pharmacological-induced overactivity of the medial thalamus could give rise to abnormal behaviors close to that observed in OCD. We modulated the ventral anterior (VA) and medial dorsal (MD) nuclei activity by in situ bicuculline (GABA $A_{A}$ antagonist) microinjections in subhuman primates and assessed their pharmacological-induced behavior. Bicuculline injections within the VA caused significant repetitive and timeconsuming motor acts whereas those performed within the MD induced symptoms of dysautonomic dysregulation along with abnormal vocalizations and marked motor hypoactivity. These findings suggest that overactivation of the VA and MD nuclei of the thalamus provokes compulsive-like behaviors and neurovegetative manifestations usually associated with the feeling of anxiety in OCD patients. In further research, this translational approach should allow us to test the effectiveness and side effects of these thalamic nuclei DBS in monkey and perhaps, in a second step, to propose a transfer of this technique to severely disabled OCD patients.

Translational Psychiatry (2012) 2, e161; doi:10.1038/tp.2012.88; published online 25 September 2012

\section{Introduction}

Obsessive-compulsive disorder (OCD) is an invalidating psychiatric disorder owing to the resulting functional disturbance. ${ }^{1}$ Obsessions may be defined as the eruption of uncontrolled intrusive thoughts. They are generally associated with a feeling of urgency or catastrophe and manifestations of anxiety. They lead to grouped repetitive behavior known as compulsions, which in turn decrease anxiety levels. ${ }^{2}$

Phenomenological considerations and neuroimaging studies have recently shed light on the putative brain regions involved in OCD pathophysiology. Increased metabolism has been reported in the orbitofrontal ${ }^{3-5}$ and anterior cingulate ${ }^{5-7}$ cortices but also in the caudate nucleus ${ }^{5,8}$ and thalamus. ${ }^{6,9,10}$ Structural abnormalities within anterior and medial thalamic nuclei have also been reported ${ }^{11-13}$ as well as morphological alterations within the thalamo-cortical network found in human OCD. ${ }^{11}$ Moreover, partial improvement of OCD symptoms was reported in severe and resistant forms of the disease after deep brain stimulation (DBS) targeting the associative and limbic territories of either the caudate nucleus ${ }^{14,15}$ or the anterior portion the subthalamic nucleus. ${ }^{16}$ Thus, it appears that in OCD, morphological and functional abnormalities are found within the associative and limbic territories of the corticosubcortical loops.

However, a lack of efficacy and unwanted side effects (hypomania, depression, anxiety and irritability) has been reported in some patients undergoing DBS of the subthalamic nucleus. ${ }^{16}$ Consequently, the search for new DBS targets remains a real challenge. Among several potential candidates, the thalamus is particularly interesting. Furthermore, sensorimotor, cognitive and limbic functional territories of both basal ganglia and the thalamus have been well identified and provide the opportunity to precisely investigate the cognitive and limbic cortico-subcortical loops through animal research. ${ }^{17,18}$ The ventral anterior (VA) and medial dorsal (MD) nuclei have a role in cognitive and emotional functions through (1) their medial nigral and ventral pallidal imputs, (2) their reciprocal connections with the three major prefrontal cortical regions,

\footnotetext{
${ }^{1}$ Univ Bordeaux, Institut des Maladies Neurodégénératives, UMR 5293, Bordeaux, France; ${ }^{2}$ Service Universitaire de Psychiatrie Adulte, Centre Hospitalier Charles Perrens, Bordeaux, France; ${ }^{3}$ Service d'Explorations Fonctionnelles du Système Nerveux, Centre Hospitalier Universitaire, Bordeaux, France and ${ }^{4}$ Univ Bordeaux, Institut des Neurosciences Cognitives et Intégratives d'Aquitaine, UMR 5287, Bordeaux, France

Correspondence: Dr D Guehl, Service d'Explorations Fonctionnelles du Système Nerveux, Centre Hospitalier Universitaire, Place Amélie Rabat Léon, Bordeaux 33076 , France.

E-mail: dominique.guehl@u-bordeaux2.fr

${ }^{5} \mathrm{NB}$ : JYR and BA were involved similarly in the paper.

Keywords: monkey; obsessive-compulsive disorder; pharmacological manipulations; thalamus

Received 31 January 2012; revised 10 July 2012; accepted 13 July 2012
} 
including the orbitofrontal cortex, the dorsolateral prefrontal cortex (DLPFC) and the anterior cingulate cortex (ACC). ${ }^{19,20}$ A large body of evidence points to the involvement of these prefrontal cortices in several cognitive and emotional subprocesses underlying behavioral responses in close relationships with thalamic inputs. ${ }^{18,21-25}$

Here, we employ a translational approach to the pathophysiology of OCD by exploring in subhuman primates the putative role of the associative and limbic parts of thalamus in compulsive-like behavior in order to carefully verify whether these structures could be potentially interesting targets for DBS in severe OCD patients in the future. We postulate that VA and MD nuclei could contribute to the emergence of OCD symptoms, especially compulsive behaviors and anxiety. To this end, we mimicked overactivity within associative and limbic cortico-subcortical loops found in functional neuroimaging studies conducted in human OCD by performing local VA and MD injections of the GABA-A antagonist bicuculline and by assessing the behavioral changes induced.

\section{Materials and methods}

Animals. Experiments were conducted on three female monkeys (Macaca mulatta) weighing $4-6 \mathrm{~kg}$, housed in individual primate cages. They had ad libitum access to water and food without supplementation with fruits. Their care was supervised by veterinarians skilled in the maintenance of subhuman primates, in strict accordance with the European Community Council Directive for experimental procedures in animals. The light-dark cycle (lights on from 0700 to 1900 hours), temperature $\left(22^{\circ} \mathrm{C}\right)$ and humidity (60\%) were kept constant in the animal room. The animals were allowed at least 2 weeks to acclimatize to the animal room before starting any manipulation. They were then trained to be seated in a primate chair with their head restrained and to remain quiet during palpation of various parts of the body.

Surgery. The surgical procedure was performed under general anesthesia using ketamine $\left(\mathrm{IM}, 10 \mathrm{mg} \mathrm{kg}^{-1}\right.$, Panpharma, Fougères, France), xylazine (IM, $2 \mathrm{mg} \mathrm{kg}^{-1}$, Bayer Pharma, Puteaux, France) and atropine sulfate (IM, $0.2 \mathrm{mg} \mathrm{kg}^{-1}$, Aguettant, Lyon, France). Additional doses of ketamine and xylazine were administered as necessary to maintain optimal anesthesia. A stainless steel chamber (Narishige, Tokyo, Japan, diameter $19 \mathrm{~mm}$ ) was implanted on the interhemispheric line over both the right and left hemispheres under aseptic conditions. The center of the cylinder was stereotaxically positioned at A13 and L0 $(-4.8 \mathrm{~mm}$ posterior to anterior commeasure and aligned with the anterior-posterior axis, respectively) in the three monkeys, according to the atlas of Szabo and Cowan, ${ }^{26}$ and the position of the anterior commissure predetermined with structural magnetic resonance imaging data. A head holder was embedded with dental cement (Omnium Dentaire, Bordeaux, France) around the chamber in order to immobilize the head of the monkeys for the experiments with drug microinjections. Antibiotics (amoxicillin, subcutaneously, $11 \mathrm{mg} \mathrm{kg}^{-1}$, Fort Dodge Santé Animale, Tours, France) and analgesics (Paracetamol, per os, $30 \mathrm{mg} \mathrm{kg}^{-1}$, UPSA, Agen, France) were given for 48-72h after surgery. Animals were left to recover 10-15 days before starting the experiments.

Drugs and procedure of administration. The main objective of this study was to increase the activity of the VA and MD thalamic nuclei in order to mimic overactivity of the limbic and associative cortico-subcortical loops. To this end, bicuculline (a $\mathrm{GABA}_{\mathrm{A}}$ antagonist) was injected in each of these thalamic nuclei. In addition, muscimol (a GABA agonist) was used as control to test the behavioral effects of associative and limbic loop inhibition. Both bicuculline and muscimol (Sigma, Lyon, France) were dissolved in sterile $0.9 \% \mathrm{NaCl}$ solution (saline) at 10 and $1 \mathrm{mg} \mathrm{ml}^{-1}$, respectively. The intra-thalamic microinjections were performed in monkeys with their head fixed and their body loosely restrained by a plastic apparatus. Before microinjection sessions, extracellular neuronal recordings of single-cell activity using tungsten microelectrodes isolated with epoxy (impedance $1-1.5 \mathrm{M} \Omega$ at $1 \mathrm{kHz}$ ) were performed in order to delineate the dorsal border of the thalamus. The electrode was moved with a micromanipulator (Narishige, MO-95) in $5-10-\mu \mathrm{m}$ increments. Neuronal activity was amplified ( $\times 10000)$, filtered $(300 \mathrm{~Hz}-3 \mathrm{kHz})$ and displayed on an oscilloscope. Spikes were selected from background activity with a window discriminator, and then processed though an analog-digital interface before being stored on a microcomputer. At each session, the cannula for microinjection (26-gauge stainless steel) (Phymep, Paris, France) was connected to a Hamilton microsyringe $(10 \mu \mathrm{l})$ via a $30-\mathrm{cm}-$ long polyethylene tube (Phymep) filled with the substance to be injected, and was then lowered through the dura mater into the thalamus with the micromanipulator. Either bicuculline $(1-3 \mu \mathrm{l})$ or muscimol $(2 \mu \mathrm{l})$ was delivered manually by progressive pressure microinjection at a rate of $1 \mu \mathrm{lmin}{ }^{-1}$ (part A of the Supplementary Figure). The cannula was maintained in position at the chosen site for at least $5 \mathrm{~min}$ after completion of the microinjection to prevent drawback of the drug. At the sites selected according to the behavioral effects of bicuculline, we injected saline as control substance by using a similar experimental procedure. Additional microinjections of muscimol were performed on the last monkey.

Heart rate recording. To record the heart rate, $\mathrm{R}-\mathrm{R}$ intervals were monitored with a tactile sensor fixed on the tail while the animal was seated in the primate chair with the head and body restrained. Recordings were made for $60 \mathrm{~s}$ immediately before and after bicuculline was injected into the MD nucleus. Data obtained with a PowerLab system were analyzed using Chart 5.0 software (ADI Instruments, Phymep).

Vocal analysis. As bicuculline injections were performed within the MD-induced vocalizations, spectral analysis of these vocalizations using the Matlab 7.0.1 software was carried out before and after injections on 90-s audio recording obtained through the microphone of the video recorder. The temporal patterns of vocal productions were also examined across both experimental conditions. 
Behavioral activity. Behavioral activity was recorded 10-15 min after each microinjection with a camera placed in front of the experimental cage during a 45-min session, which was divided into three consecutive 15-min periods of observation (P1, P2 and P3). During this period, the animals were placed in a $1.0 \times 1.3 \times 0.8 \mathrm{~m}^{3}$ clear plastic cage with a metal-barred floor (part B of the Supplementary Figure). Behavioral activity was analyzed with Vigiprimate software (Viewpoint, Lyon, France), which discriminates three levels of movements: (1) 'low', corresponding to immobility or absence of movement; (2) 'middle', corresponding to movement without displacement, such as grooming, toy manipulation, food intake, and so on; and, (3) 'high', corresponding to displacement within the cage, which may represent a measurement of exploration. These measures were performed after adjustments of parameter sensitivity for movement detection for each of the three animals.

To further characterize spontaneous behaviors and their occurrence, each specific behavior was counted by both direct observation and examination on videotape and quantified in terms of frequency and duration using Labwatcher software (Viewpoint; part $C$ of the Supplementary Figure). Six major kinds of behaviors were analyzed: grooming, food seeking, food intake, toy manipulation, exploration and rest. Measurements were made for the 45 min of the experimental session over 3-min intervals and conducted by the same trained researcher (BA).

General experimental design. At 10 to 15 days after surgery, the animal was acclimatized to be seated in the primate chair placed in the microinjection room where the stainless steel chamber with dura mater was cleaned with the head completely immobilized for 10-15 min. However, at this first stage, no pharmacological microinjection was performed. The animal was then transferred to the room containing the experimental cage where behaviors were monitored for a daily 45-min session after optimal sensitivity setting for movement detection, as determined on the first three consecutive sessions. After this initial 3-week habituation period, experimental sessions for intra-thalamic microinjections of bicuculline began. They included four successive observation sequences as follows: (1) 5-min observation, after the animal was transferred to the microinjection room with the cannula inserted into the intrathalamic site and before bicuculline microinjections; (2) 5-min observation, between bicuculline microinjections and cannula removal; (3) 5-min observation, after removal of the apparatus for movement restriction while the animal was still seated in the primate chair; and (4) 45-min observation after the animal was transferred to the experimental cage for recording of behavioral activity over three successive 15-min periods (P1, P2 and P3). Thereafter, the animal returned to the home cage. Muscimol or saline injections were systematically performed at sites for which behavioral disorders were induced by bicuculline injections. Microinjection sessions were separated by at least one additional session in the baseline condition, in which all the previously described manipulations were performed but without descending the cannula into the brain to detect any acquisition of contextually conditioned behaviors. Animals were systematically manipulated by the same researchers (BA, JYR and DG) across all experiments in order to avoid possible contextrelated behavioral changes.

Histological verifications. At the end of the experiments, monkeys were deeply anesthetized with an overdose of ketamine and perfused through the ascending aorta with $500 \mathrm{ml}$ of $0.9 \%$ saline, followed by 21 of $4 \%$ paraformaldehyde in phosphate buffer $(\mathrm{pH} 7.4)$ as fixative. The brain was removed from the skull, frozen and serially sliced into $50-\mu \mathrm{m}$ coronal sections. Locations of microinjection sites were then reconstructed from cresyl violet-stained and calbindinimmunoreactive sections, on the basis of a schematic representation taking into account all behavioral data collected from the three monkeys and the type of microinjection performed in each structure of interest.

Statistical analyses. Paired Student $t$-tests were used for intra-structure comparisons of the effects of both active pharmacological treatments (bicuculline and muscimol) on behavioral activity scores to those of the control substance (saline) within each of the intra-thalamic sites considered (VA and MD). Paired Student $t$-tests were also performed for inter-structure comparisons of behavioral changes produced by muscimol between both intra-thalamic sites (VA and MD). For all statistical analyses, $P<0.05$ was used as the threshold for statistical significance.

\section{Results}

Spontaneous behavior after saline injections. Working with subhuman primates, which develop specific behaviors with high inter-individual variability, involves describing the natural behavioral register of each animal. Before studying the consequences of pharmacological manipulations of the medial thalamus, it is critical to describe the spontaneous behavior of each animal during sessions of saline injection. At the beginning of experimental sessions, all monkeys ate fruits and then peanuts placed in a small container situated on the cage floor. They were sitting quietly during eating. Sometimes, monkeys $\mathrm{B}$ and $\mathrm{C}$ explored under the barrels of the cage floor to retrieve peanuts that had previously fallen down. After this eating period and until the end of the experimental session, they quietly observed the environment, either remaining seated on the cage floor (monkey A) or after climbing to the lateral barrels of the cage (monkeys $B$ and $\mathrm{C}$ ). Short sessions of injection chamber grooming (all three monkeys) or grooming of different body parts (monkey C) were observed in the three animals. Exploration of the cage by climbing the bars was common in monkeys $B$ and $C$ and rare in monkey $A$. The toys were rarely manipulated (monkey $\mathrm{C}$, only). None of the animals exhibited vocalization throughout the entire experimental session and no stereotypy was observed.

Behavioral effects of bicuculline microinjections into the VA nucleus. Postmortem histological examination of cannula tracks revealed that 8 of 14 bicuculline microinjections were indeed performed in the VA nucleus (Figure 1). As 
shown in Table 1, they caused repetitive behaviors including: (i) seeking behavior for food hidden in litter under the floor bars of the experimental cage; (ii) meticulous and unusual toy manipulations with thumb and index finger grip; and (iii) excessive grooming with examination and licking of various body parts, especially the trunk, tail, legs and finger. Moreover, emotional changes with aggressiveness and agitation occurred when these repetitive behavioral sequences were interrupted by removing the animal from the cage at the end of the experimental session.

Owing to apparent similarities with compulsions in humans, repetitive behaviors occurring after microinjections of bicuculline into the VA nucleus were qualified as 'compulsive-like behaviors'. The current nosological classifications define compulsions as time-consuming behaviors that take up at least $1 \mathrm{~h}$ per day, that is, approximately more than $7.5 \%$ of the diurnal activity period for humans suffering from OCD. We adopted a more restrictive definition by considering compulsive-like behaviors as spending over $20 \%$ of the time on such activity during at least one of the three 15-min experimental periods of observation (P1, P2 and P3). Six of the eight microinjections induced repetitive behaviors that fulfilled these duration criteria as early as the first $15 \mathrm{~min}$ (P1) after the animal was placed in the experimental cage (that is, between 15 to 30 min after bicuculline was infused into the VA nucleus), and which persisted over the two subsequent 15-min periods (P2 and P3) in all of them. The two other microinjections produced behavioral changes at $\mathrm{P} 1$, but met the predefined criterion only at either P2 and P3 or P3 (Table 1). Bicuculline injections resulted in an exacerbation of the three abovementioned behaviors, performed for a significantly longer time compared with saline administered at the same anatomical site within the VA nucleus $(t=9.57$, $P<0.0001$ ) (Figure 2a).

\begin{abstract}
Behavioral effects of bicuculline microinjections into the MD nucleus. Histological examination of the cannula track revealed that 17 of 29 bicuculline microinjections were performed within the MD nucleus in the three animals (Figure 1). As shown in Table 1, they induced severe symptoms of dysautonomic dysregulation, including heart rate fluctuations, paleness, nausea, vomiting, salivation, urination, defecation, generalized body shudder and abnormal vocalizations, which abruptly appeared within a few minutes (3-5 min) following administration, whereas the animals were seated in the primate chair. For two microinjections (B24 and B25), a dose of diazepam ( $0.5 \mathrm{mg} \mathrm{kg}^{-1}$, intramuscular) had to be administered owing to the intensity of the dysautonomic episodes, partially antagonizing the effects of bicuculline. As illustrated in Figure 2, measurements of the R-R space became highly variable after bicuculline microinjection, with a wide distribution of $\mathrm{R}-\mathrm{R}$ values collected over $60 \mathrm{~s}$ (range: $0.18-0.73 \mathrm{~s}$; Figure $2 \mathrm{c}$ ) in contrast to the relatively stable
\end{abstract}

profile found during the similar time period before bicuculline injection (range: $0.24-0.30 \mathrm{~s}$; Figure 2d). Analysis of the acoustic spectrum revealed that bicuculline injections induced vocalizations over a wider frequency range (4841394 vs $555-579 \mathrm{~Hz}$ ) with a higher peak fundamental frequency ( 890.4 vs $559.0 \mathrm{~Hz}$; Figure 2e) compared with those spontaneously produced by the animal before injection (Figure 2f). Vocalizations also occurred more frequently and regularly (Figure 2e, lower trace), as attested by their higher number (25 vs 10) and shorter inter-vocalization interval (1.65-5.21 vs 3.24-20.06 s) over the $90 \mathrm{~s}$ of audio recording.

These behavioral manifestations were followed by a profound motor hypoactivity with marked fatigue and reduced vigilance. This led to a substantial reduction in spontaneous displacement and exploratory behaviors in the experimental cage, which were marked as early as P1 for 10 microinjections, and extended at P2 for two of them, or P2 and P3 for five of them. For the five other microinjections, such behavioral changes started at $\mathrm{P} 1$ but became prominent at P2 for one of them, at P2 and P3 for three others or at P3 for the other one (Table 1). Bicuculline significantly suppressed both displacement and exploratory activities when compared with saline injected at the same anatomical site of the MD ('high' activity duration: $t=6.29, P<0.0001$; exploratory activity duration: $t=7.43, P<0.0001$ ) (Figure $2 \mathrm{~b}$ ).

Behavioral effects of muscimol microinjections into the VA and MD nuclei. To study the effect of strengthening GABAergic transmission (inhibition of intra-thalamic GABAergic interneurons and inhibition of the projection thalamic neurons ${ }^{27}$ ), we performed muscimol microinjections. Postmortem histological examination of cannula tracks revealed that 7 out of 10 were performed within the medial thalamus (four in the VA and three in the MD) in one of the three animals (Figure 1). Whatever the site of injection, muscimol induced a very similar behavioral pattern after injections in both nuclei. Indeed, marked motor hyperactivity with disruptive behavior was observed after injections in both intrathalamic sites (Table 2). Muscimol injections resulted in a larger number of specific behavioral sequences in the VA $(t=9.49, \quad P<0.0001)$ and $\operatorname{MD}(t=2.24, \quad P<0.03)$ nuclei (Figure $3 a$ ). Comparative analysis of the three microinjections performed within the VA and MD nuclei, where muscimol produced locomotor effects throughout the three periods considered (P1, P2 and P3), showed higher behavioral changes in the VA than in the MD (high activity duration: $t=13.84, P<0.0001$; exploratory activity duration: $t=9.48$, $P<0.0001$; behavior frequency: $t=5.40, P<0.0001$ ).

There was also a major increase in exploratory activity and excessive displacements in the experimental cage with disorganized behavioral sequences owing to successive and rapid shifting from one behavior to another (Figure 3b). Such profound behavioral disturbances were observed at P1, P2

Figure 1 Anatomical localization of microinjection sites of either bicuculline or muscimol with related behavioral effects in the thalamic ventral anterior (VA) and medial dorsal (MD) nuclei. AC, anterior commissure; cc, corpus callosum; Cd, caudate nucleus; CM, centrum medianum; fx, fornix; GP, globus pallidus; ic, internal capsule; LH, lateral hypothalamic area; LP, lateral posterior nucleus; IV, lateral ventricle; opt, optic tract; PF, parafascicular nucleus; Pu, putamen; Pul, pulvinar; Rt, reticular nucleus; SNr, substantia nigra, pars reticulata; STN, subthalamic nucleus; VLc, ventral lateral nucleus, pars caudalis; VLo, ventral lateral nucleus, pars oralis; VLm, ventral lateral nucleus, pars medialis; VPLo, ventral posterior lateral nucleus, pars oralis. 


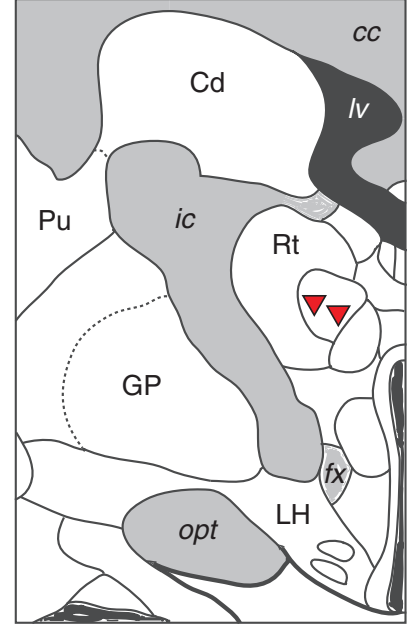

AC -3

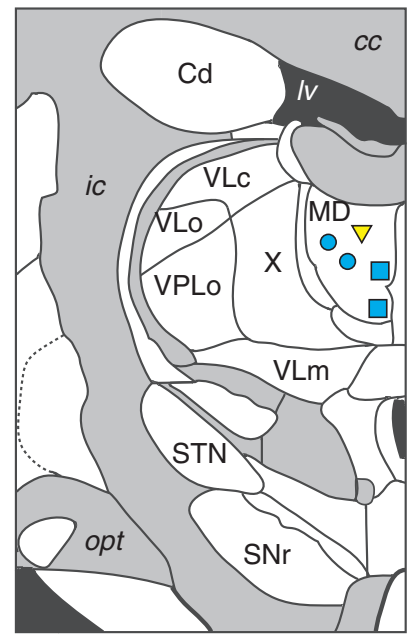

AC -6

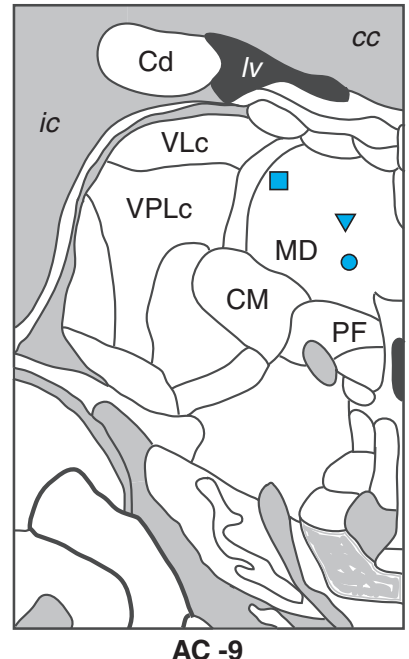

- Monkey A

$\square$ Monkey B

$\nabla$ Monkey C

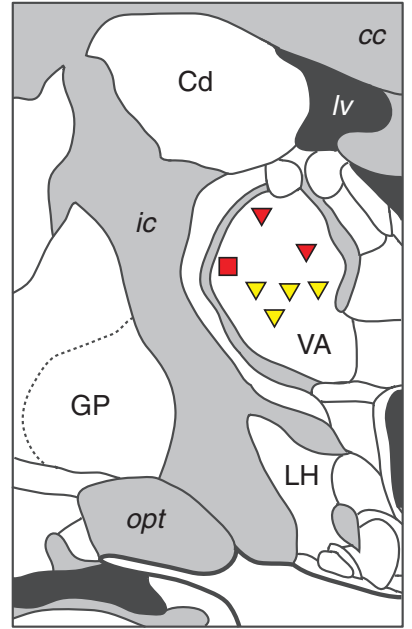

AC -4

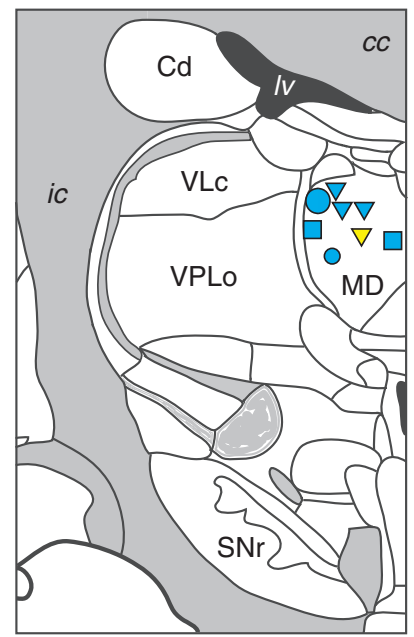

AC -7

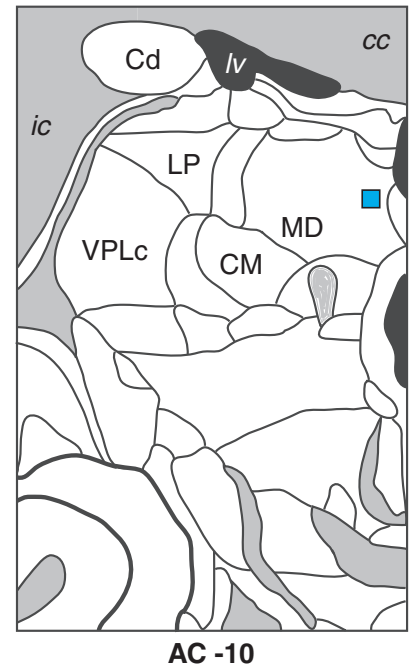

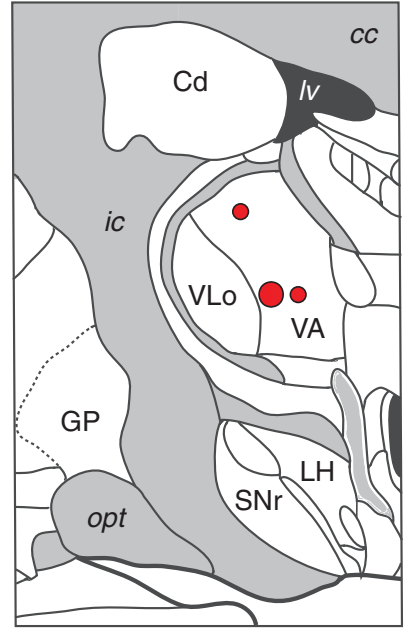

AC -5

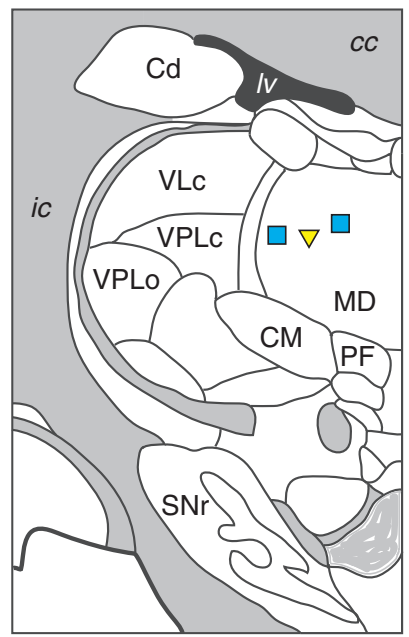

AC -8

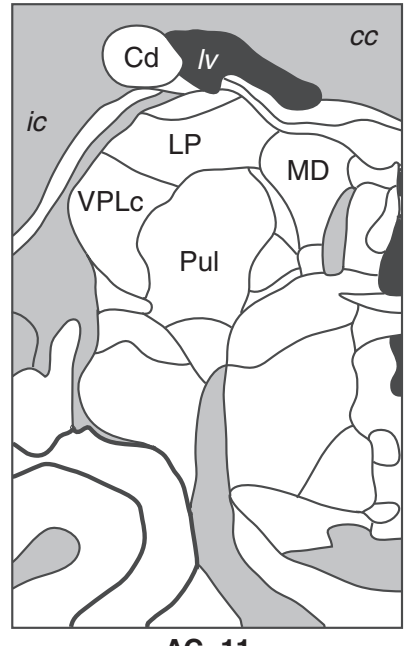

AC -11

- Compulsive-like behaviors (bicuculline/VA)

- Motor inhibition with dysautonomic syndrome (bicuculline/MD)

- Locomotor hyperactivity (muscimol/VA-MD) 
Table 1 Behavioral effects of bicuculline microinjections into the VA nucleus and the MD nucleus

\begin{tabular}{|c|c|c|c|c|c|c|c|}
\hline \multirow[t]{2}{*}{ Injection } & \multirow[t]{2}{*}{ Monkey } & \multirow[t]{2}{*}{ Side } & \multirow{2}{*}{$\begin{array}{c}\text { Dose in } \mu g \\
\text { (volume in } \mu l)\end{array}$} & \multirow{2}{*}{$\begin{array}{l}\text { Behaviors } \\
\text { in chair }\end{array}$} & \multicolumn{3}{|c|}{ Abnormal behaviors in the experimental cage $e^{a}$} \\
\hline & & & & & $P 1$ & $P 2$ & P3 \\
\hline \multicolumn{8}{|c|}{ Microinjections into the VA } \\
\hline B1 & A & $\mathrm{R}$ & $10(1)$ & None & Food seeking & Food seeking & Food seeking/grooming \\
\hline $\mathrm{B} 2$ & A & $\mathrm{R}$ & $10(1)$ & None & Food seeking & Food seeking/Grooming & Grooming \\
\hline B3 & A & $\mathrm{L}$ & $10(1)$ & None & - & Grooming & Food seeking/grooming \\
\hline B4 & $B$ & $\bar{L}$ & $10(1)$ & None & - & - & Food seeking \\
\hline B5 & $\mathrm{C}$ & $\mathrm{L}$ & $10(1)$ & None & Toy manipulation & Toy manipulation & Toy manipulation \\
\hline B6 & C & $\mathrm{R}$ & $10(1)$ & None & Toy manipulation & Toy manipulation & Toy manipulation/grooming \\
\hline B7 & $\mathrm{C}$ & $\mathrm{R}$ & $20(2)$ & None & Toy manipulation/food seeking & Toy manipulation/food seeking & Grooming \\
\hline B8 & C & $\mathrm{L}$ & $30(3)$ & None & Food seeking & Grooming & Toy manipulation \\
\hline \multicolumn{8}{|c|}{ Microinjections into the $M D$} \\
\hline B9 & A & $\mathrm{L}$ & $10(1)$ & AV-DS & Motor hypoactivity & Motor hypoactivity & Motor hypoactivity \\
\hline B10 & A & $\mathrm{R}$ & $10(1)$ & AV-DS & Motor hypoactivity & - & - \\
\hline B11 & A & $\mathrm{R}$ & $10(1)$ & AV-DS & — & - & Motor hypoactivity \\
\hline B12 & A & $\mathrm{R}$ & $10(1)$ & AV-DS & Motor hypoactivity & - & — \\
\hline $\mathrm{B} 13$ & A & $\mathrm{L}$ & $10(1)$ & AV-DS & - & Motor hypoactivity & Motor hypoactivity \\
\hline B14 & $\mathrm{B}$ & $\mathrm{R}$ & $10(1)$ & AV-DS & - & Motor hypoactivity & — \\
\hline B15 & $\mathrm{B}$ & $\mathrm{R}$ & $10(1)$ & AV-DS & Motor hypoactivity & — & - \\
\hline B16 & B & $\mathrm{L}$ & $10(1)$ & AV-DS & - & Motor hypoactivity & Motor hypoactivity \\
\hline B17 & B & $\mathrm{R}$ & $10(1)$ & AV-DS & Motor hypoactivity & Motor hypoactivity & Motor hypoactivity \\
\hline B18 & $\mathrm{B}$ & $\mathrm{R}$ & $20(2)$ & AV-DS & Motor hypoactivity & Motor hypoactivity & - \\
\hline B19 & $\mathrm{B}$ & $\mathrm{L}$ & $20(2)$ & AV-DS & Motor hypoactivity & Motor hypoactivity & Motor hypoactivity \\
\hline B20 & $\mathrm{B}$ & $\mathrm{L}$ & $20(2)$ & AV-DS & Motor hypoactivity & Motor hypoactivity & Motor hypoactivity \\
\hline $\mathrm{B} 21$ & $\mathrm{~B}$ & $\mathrm{R}$ & $30(3)$ & AV-DS & Motor hypoactivity & Motor hypoactivity & — \\
\hline B22 & $\mathrm{C}$ & $\mathrm{R}$ & $20(2)$ & AV-DS & - & Motor hypoactivity & Motor hypoactivity \\
\hline B23 & $\mathrm{C}$ & L & $20(2)$ & AV-DS & Motor hypoactivity & Motor hypoactivity & Motor hypoactivity \\
\hline B24 & $\mathrm{C}$ & $\mathrm{R}$ & $20(2)$ & AV-DS & Intramuscular injection of diazep & $\operatorname{pam}\left(0.5 \mathrm{mg} \mathrm{kg}^{-1}\right)$ & \\
\hline B25 & $\mathrm{C}$ & $\mathrm{R}$ & $30(3)$ & AV-DS & Intramuscular injection of diazep & oam $\left(0.5 \mathrm{mg} \mathrm{kg}^{-1}\right)$ & \\
\hline
\end{tabular}

Abbreviations: AV, abnormal vocalizations; DS, dysautonomic syndrome; L, left; MD, medial dorsal; R, right; VA, ventral anterior.

${ }^{a}$ Repetitive behaviors were mentioned when the duration criteria were fulfilled.

and P3 with 6 of the 7 microinjections and were limited to P1 with the remaining one (Table 2). There was a significant increase in high activity duration measured with quantitative actimetry after bicuculline vs saline injections into either the VA $(t=11.64, P<0.0001)$ or $\operatorname{MD}(t=4.82, P<0.0001)$ nuclei. Duration of exploratory activity quantified using the ethological keyboard was also increased after muscimol injections in comparison with saline both in the VA $(t=13.83, P<0.0001)$ and $\mathrm{MD}(t=7.23, P<0.0001)$ nuclei (Figure $3 \mathrm{~b})$.

Behavioral effects of bicuculline microinjections in other thalamic sites. Histological examination of cannula tracks revealed that 18 bicuculline microinjections were performed in motor thalamic sites, including the pallidal thalamus (VLo: ventrolateral thalamic nucleus, pars oralis, $n=6$ ) or its cerebellar territory (VLc: ventrolateral thalamic nucleus, pars caudalis/VPLo: ventral posterior lateral thalamic nucleus, pars oralis, $n=12$ ). They induced either severe postural abnormalities such as cervical dystonia with ipsilateral inclination and head rotation or myoclonic jerks involving the contralateral upper and lower limbs. Two microinjections performed at the border between VLc/VPLo, VA and MD nuclei induced a sequence of three successive behaviors: immediate but transient dystonic limb spasms followed by repetitive behavior and then motor hypoactivity.

\section{Discussion}

To our knowledge, this study is the first to show that pharmacological manipulations of the associative and limbic parts of the thalamus induce dramatic changes in behavior. While bicuculline injections within the VA produced repetitive food seeking and body grooming along with unusual manipulation of available toys, the same type of injections within the MD induced profound motor hypoactivity with severe dysautonomic manifestations, such as heart rate variation, paleness, salivation, vomiting, urination and defecation. Conversely, a marked hyperactivity with severely disorganized and incompletely executed behaviors was observed after muscimol injections in both the VA and MD. Within the thalamus, the inhibitory neurotransmitter GABA is involved in the intrinsic mechanisms regulating the activity of the glutamatergic neurons that project to cortical areas (GABAergic interneurons). Bicuculline is a $\mathrm{GABA}_{A}$ receptor antagonist that reduces intra-thalamic GABAergic tone ${ }^{28}$ and consequently may induce cortical activation through disinhibition of the thalamo-cortical pathway. In contrast, muscimol is a $\mathrm{GABA}_{\mathrm{A}}$ receptor agonist that enhances intra-thalamic GABAergic tone and produces an inhibition of the thalamo-cortical pathway.

Behavioral disorders induced by pharmacological manipulations of the VA. Bicuculline microinjections within the VA exacerbated a range of spontaneous behaviors that shares some similarities with the compulsions observed in human subjects suffering from OCD. These behaviors correspond to the natural behavioral register of these animals but their frequency was clearly enhanced to dramatic levels by pharmacological manipulations of this thalamic nucleus. Consequently, they cannot be considered as 

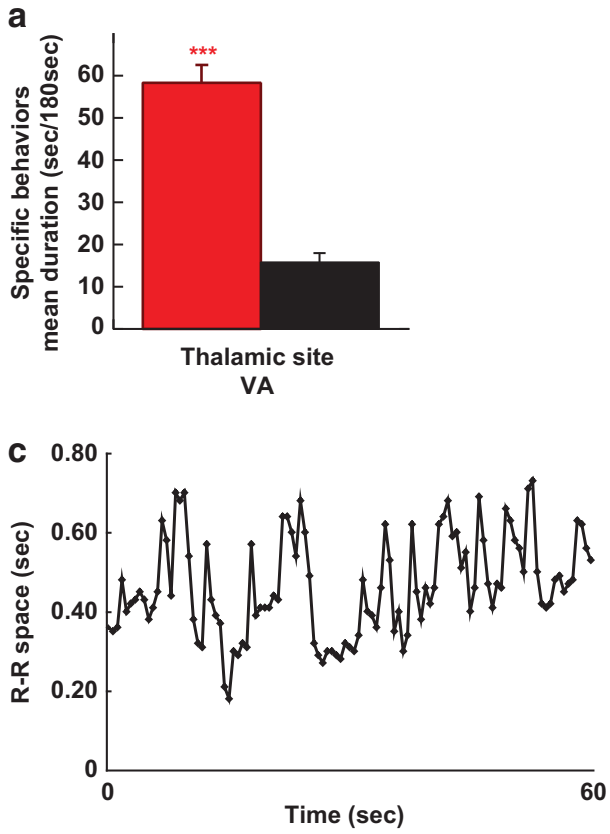

e

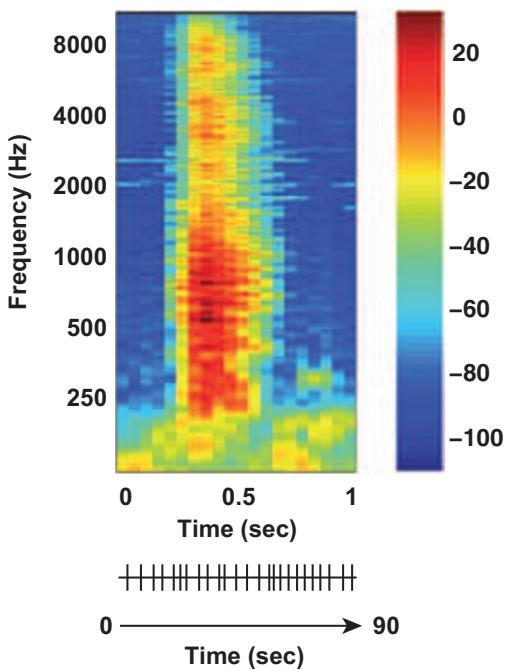

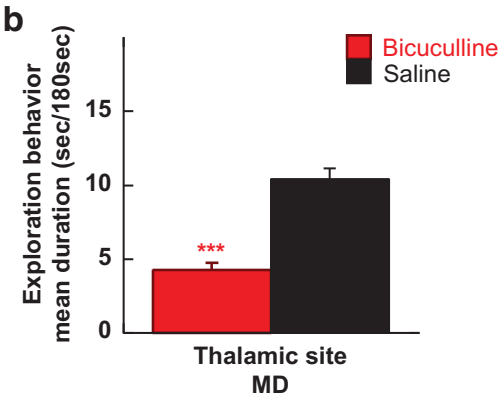
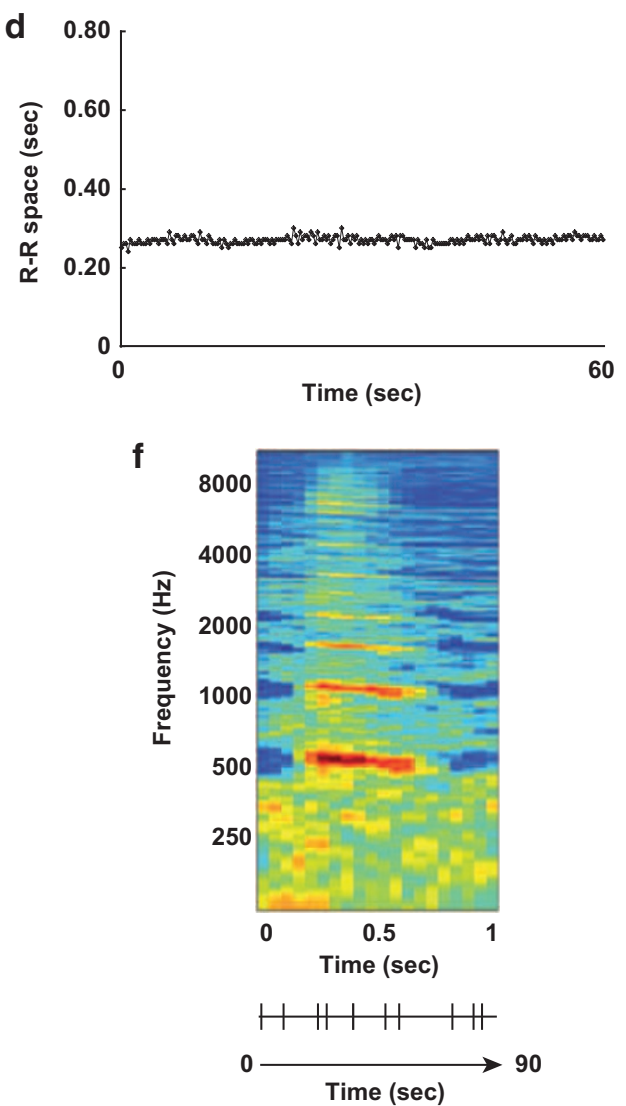

Figure 2 Behavioral effects of bicuculline microinjections within the ventral anterior (VA) or medial dorsal (MD) thalamic nuclei of the three animals studied. (a) In the VA nucleus, bicuculline produced a significant increase in the amount of time spent on three spontaneously committed behaviors (i.e., food seeking, toy manipulation and body grooming) in comparison with saline administered at the same anatomical site. (b) In the MD nucleus, bicuculline resulted in profound motor hypoactivity, as shown by a significantly reduced amount of time spent in exploratory activity compared with that observed in response to saline microinjection performed at the same anatomical site (significantly different from saline: ${ }^{* \star} P<0.001$ ). (c) A 60-s recording of the R-R space after and (d) immediately before bicuculline microinjection (B22) in the thalamic MD nucleus. Relative to the experimental condition, heart rate was irregular in response to bicuculline administration, as attested by profound fluctuations in the R-R space over time. (e, f) Example of individual spectrographic analysis for the comparison of vocalizations after (e) and immediately before (f) bicuculline microinjection (B22) in the thalamic MD nucleus. Bicuculline resulted in vocalizations of wider frequency range with higher peak fundamental frequency (e) and rhythm over $90 \mathrm{~s}$ (e lower trace) of audio recording than those spontaneously produced by the animal (f).

stereotypies. Stereotyped behavior is considered as a set of repetitive motor activities, rhythmic, coordinated with a precise pattern but non-goal-directed. ${ }^{29,30}$ On the other hand, the repetitive behaviors exhibited by our monkeys and that share similarities with human compulsions are complex and goal-directed motor activities without any rhythmic or precise motor pattern characteristic. Stereotypies are observed after bicuculline injections within the limbic territory of the external globus pallidus (that is, GPe) ${ }^{31}$ or the ventral striatum (that is, VS). ${ }^{32}$ In these conditions, an intense expression of repetitive behaviors forming part of the animal's usual repertoire such as tail- or finger-biting and licking of the cage bars was observed. They differ from the complex organized behavioral sequences observed in our study. This could be owing either to the nature of the target (GPe or VS vs VA) or to the experimental context. Both the limbic territory of the GPe and VS are densely connected to the pars reticularis of the substantia nigra, ${ }^{33-35}$ which in turn 
sends vast projections to the VA nucleus but also to more motor territory of the thalamus. ${ }^{19}$ Information arising from the basal ganglia is not simply carried throughout the VA nucleus but is processed and synthesized with information coming from other sources before reaching the cortical level. ${ }^{36}$ This might explain why behaviors obtained after pharmacological manipulation of the medial thalamus are more organized than that observed after GPe or VS manipulations. Alternatively, in our work, monkeys were left to move freely in their experimental cage with access to food and toys whereas they were restrained over a long period of time in a primate chair in the study by the Tremblay's team. ${ }^{31,32}$ Increasing the level of stress, this situation could induce a stereotypic pattern. Indeed, the latter appears more frequently in adverse environmental conditions than in freemoving spaces. ${ }^{37,38}$

Interestingly, the grooming behavior observed in our monkeys is relatively similar to the cleaning and washing

Table 2 Behavioral effects of muscimol microinjections into the VA nucleus and the MD nucleus

\begin{tabular}{|c|c|c|c|c|c|}
\hline \multirow[t]{2}{*}{ Injection } & \multirow[t]{2}{*}{ Side } & \multirow{2}{*}{$\begin{array}{c}\text { Dose in } \mu g \\
\text { (volume in } \\
\mu \mathrm{l})\end{array}$} & \multicolumn{3}{|c|}{$\begin{array}{c}\text { Abnormal behaviors in the experimental } \\
\text { cage }\end{array}$} \\
\hline & & & $P 1$ & $P 2$ & P3 \\
\hline \multicolumn{6}{|c|}{ Microinjections into the VA } \\
\hline M1 & $\mathrm{R}$ & $2(2)$ & $\begin{array}{l}\text { Motor } \\
\text { hyperactivity }\end{array}$ & $\begin{array}{l}\text { Motor } \\
\text { hyperactivity }\end{array}$ & $\begin{array}{l}\text { Motor } \\
\text { hyperactivity }\end{array}$ \\
\hline M2 & $\mathrm{R}$ & $2(2)$ & $\begin{array}{l}\text { Motor } \\
\text { hyperactivity }\end{array}$ & $\begin{array}{l}\text { Motor } \\
\text { hyperactivity }\end{array}$ & $\begin{array}{l}\text { Motor } \\
\text { hyperactivity }\end{array}$ \\
\hline M3 & $\mathrm{L}$ & $2(2)$ & $\begin{array}{l}\text { Motor } \\
\text { hyperactivity }\end{array}$ & $\begin{array}{l}\text { Motor } \\
\text { hyperactivity }\end{array}$ & $\begin{array}{l}\text { Motor } \\
\text { hyperactivity }\end{array}$ \\
\hline M4 & $\mathrm{L}$ & $2(2)$ & $\begin{array}{l}\text { Motor } \\
\text { hyperactivity }\end{array}$ & - & - \\
\hline \multicolumn{6}{|c|}{ Microinjections into the $M D$} \\
\hline M5 & $\mathrm{R}$ & $2(2)$ & $\begin{array}{l}\text { Motor } \\
\text { hyperactivity }\end{array}$ & $\begin{array}{l}\text { Motor } \\
\text { hyperactivity }\end{array}$ & $\begin{array}{l}\text { Motor } \\
\text { hyperactivity }\end{array}$ \\
\hline M6 & $\mathrm{R}$ & $2(2)$ & $\begin{array}{l}\text { Motor } \\
\text { hyperactivity }\end{array}$ & $\begin{array}{l}\text { Motor } \\
\text { hyperactivity }\end{array}$ & $\begin{array}{l}\text { Motor } \\
\text { hyperactivity }\end{array}$ \\
\hline M7 & $\mathrm{R}$ & $2(2)$ & $\begin{array}{l}\text { Motor } \\
\text { hyperactivity }\end{array}$ & $\begin{array}{l}\text { Motor } \\
\text { hyperactivity }\end{array}$ & $\begin{array}{l}\text { Motor } \\
\text { hyperactivity }\end{array}$ \\
\hline
\end{tabular}

Abbreviations: L, left; MD, medial dorsal; R, right; VA, ventral anterior. compulsions experienced by human patients. These behaviors were time-consuming as they substantially interfered with the animal's routine activity. The duration criteria we used to define compulsive-like behavior were more restrictive than those currently used for defining compulsive behaviors in humans. We also observed a marked agitation with aggressiveness when the ongoing compulsive-like behavior was interrupted by the experimenter at the end of the experimental session. To some extent, this behavior is similar to the rebound of anxiety symptoms experienced by OCD subjects when they are unexpectedly asked to stop recurrent ritualized behaviors. The thalamic VA nucleus has anatomical and functional relationships with limbic structures, such as the amygdala, ${ }^{39}$ which has been consistently identified as having a crucial role in both the perception of emotionally salient information and the production of emotional responses. ${ }^{40}$ Therefore, an abnormally elevated activity within the amygdala, as thought to occur in response to bicuculline injected into the VA nucleus, could produce the emergence of aggressiveness like that observed in our study.

Bicuculline-induced repetitive and meticulous body grooming, food seeking and toy manipulation suggest that the animals pay excessive attention to environmental stimuli. One explanation could be that bicuculline injections impact on attentional processes through the overactivation of the DLPFC and ACC to which the VA projects. ${ }^{19,20}$ Neuroimaging studies indicate that the ACC is involved in a variety of cognitive processes, including attention to action (for review, $\mathrm{see}^{41}$ ). The cognitive region of the ACC (areas $24 \mathrm{~b}^{\prime}-\mathrm{c}^{\prime}$ and $32^{\prime}$ ) is part of an attentional network and is closely connected with the DLPFC, premotor and parietal cortices (for review, $\mathrm{see}^{22}$ ). Some authors reported overactivity within the ACC and reinforcement of connectivity in the ACC-DLPFC network in OCD patients. ${ }^{42,43}$ The latter data are in accordance with the hypothesis of an increased attention to environmental stimuli, suggested by the monkey's behavior related to bicuculline-induced overactivation of the thalamo-cortical pathway. A limitation of the present study was that the level of attention before and after injection was not evaluated in standardized conditions. Conversely, injection of the $\mathrm{GABA}_{A}$ receptor agonist muscimol into the VA induced a disorganization of behavior with severe motor hyperactivity reminiscent of
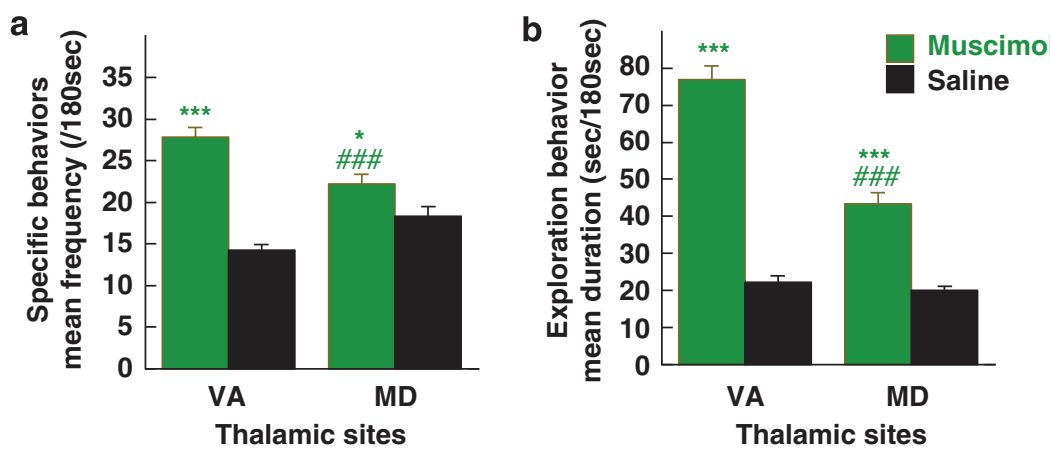

Figure 3 Behavioral effects of muscimol microinjections within the ventral anterior (VA) or medial dorsal (MD) thalamic nuclei in one of the three animals studied. (a) In the VA nucleus, muscimol caused a rapid shift from one behavioral sequence to another, as suggested by a significantly higher frequency of the different types of specific behavior recorded. (b) Muscimol also produced motor hyperactivity, as attested by a significantly greater amount of time spent in exploratory behavior than that found after saline administration at the same anatomical site. In the MD nucleus, muscimol gave rise to similar behavioral changes, although less pronounced than those observed in the VA nucleus $(\mathbf{a}, \mathbf{b})$ (significantly different from saline: ${ }^{* \star} P<0.001,{ }^{\star} P<0.05$; significantly different from muscimol injected into the VA: \#\#\# $P<0.001$ ). 
the attention deficit/hyperactivity disorder observed in human patients.

Behavioral disorders induced by pharmacological manipulations of the MD. Bicuculline microinjections within the MD nucleus of the thalamus gave rise to a dramatic form of dysautonomia with repetitive and rhythmic vocalizations followed by a profound anergia and vigilance fluctuations. Anatomically, the MD nucleus has bidirectional connections with the amygdala through its lateral and basolateral nuclei. ${ }^{44,45}$ In turn, these nuclei project to the central nucleus of the amygdala, which then extensively innervates a wide range of brain target structures that subsume specific clinical aspects of emotional responses. ${ }^{46}$ The connections between the central nucleus of the amygala and both the lateral hypothalamus and related dorsal motor nucleus of the vagus could be responsible for sympathetic and parasympathetic autonomic nervous system disorder accounting for dysautonomic disorders, such as heart rate variation, paleness, salivation, vomiting, urination, defecation or body shudder. The ACC, which receives inputs from the thalamic MD nucleus and sends outflow to the amygdale, ${ }^{19,20}$ is another candidate for the regulation of emotional responses with autonomic components ${ }^{21-23}$ as well as the direct pathway that links the hypothalamus and MD nucleus of the thalamus. $^{47-49}$

The question remains, however, why MD and VA disinhibition with bicuculline lead only to 'compulsive-like' behaviors in the VA and to vegetative effects in the MD. Regarding the anatomical connections, the VA nucleus is linked to the amygdala, a region that is known to have a critical role in the expression of aggressiveness. ${ }^{39,40}$ The MD nucleus has stronger connections than the VA with structures especially involved in neurovegetative modulation. Indeed, the MD nucleus establishes connections with the lateral and the dorsomedial nuclei of the hypothalamus, to the dorsal motor nucleus of the vagus through the central nucleus of amygdala, to the prelimbic and VA cingulate areas, medial orbital and ventral agranular insular areas and finally to the lateral preoptic area. ${ }^{45,46,50,51}$ Thus, this organization could explain why bicuculline injections induce differential behavioral manifestations according to the thalamic nucleus. Indeed, bicuculline injections in the VA nucleus induce 'compulsivelike' behavior while bicuculline injections in the MD nucleus induce strong vegetative manifestations that probably mask underlying cognitive impairments that could be observed in these experimental conditions.

Neurovegetative manifestations linked to anxiety are observed in human OCD patients experiencing acute panic attacks. ${ }^{21,52}$ Our data in the monkey suggest that vegetative manifestations induced by MD nucleus overactivity could be related either to physical manifestations of anxiety or isolated vegetative manifestations occurring independently of any anxiety dimension. However, the latter is very difficult to apprehend in monkey and this interpretation should be taken cautiously. The induction of vocalizations by bicuculline is of particular interest because vocalizations belong to the normal interindividual communication repertory of this subhuman species. In our experiments, these vocalizations had some features of stereotypies with a periodic occurrence and a constant tone of voice, which could be considered as reflecting high anxiety levels. From an anatomical point of view, projections of the central nucleus of the amygdala to the periacqueductal gray region, which is thought to be involved in the elicitation of vocalization, ${ }^{46,53}$ could mediate these anxiety-liked vocalizations. Interestingly, sudden, intense and repetitive vocalizations are also observed in Tourette's syndrome, ${ }^{54-56}$ a frequently comorbid OCD condition, where a malfunction of the thalamus has been reported. ${ }^{21,54,55,57}$

Finally, muscimol injections in the MD were also responsible for the occurrence of inappropriate and disruptive hyperactivity but they were less marked than after VA injections. Our observation confirms the results of previous studies in rodents showing a dose-dependent increase in locomotor response to muscimol in the MD nucleus. ${ }^{58,59}$ Thus, it can be assumed that the MD shares, at least partially with the VA, some common cortical projection areas such as the DLPFC and ACC ${ }^{19,20}$ which are of special importance in regulating cognitive functions and controlling attentional processes. 24,60

\section{A role of the associative and limbic parts of the thalamus} in anxiety-like disorders and repetitive behavior. To date, the involvement of the associative and limbic thalamic nuclei in the expression of compulsive-like behaviors similar to those observed in OCD patients has not been reported. Our findings show that the VA nucleus could be involved in the production of compulsive-like behaviors, whereas the MD participates rather in the monitoring of associated emotional responses with dysautonomic concomitants. Therefore, our findings underline the critical importance of the associative and limbic parts of the thalamus in behavioral disorders that have formal similarities with OCD. Although the exact mechanisms of DBS remain unclear, this technique seems to regularize neuronal activity in a given target. ${ }^{61-63}$ The thalamus is a long-lasting target for DBS in essential tremor, Parkinson's disease, Dystonia and Tourette's syndrome. ${ }^{64,65}$ Our original observation should allow us to test the effectiveness and safety of thalamic DBS in primate in a subsequent study. Thereafter, if the results of such a study are encouraging, we could consider DBS of these thalamic targets or one of them in severely disabling forms of OCD in human.

\section{Conflict of interest}

The authors declare no conflict of interest.

Acknowledgements. We thank Dr Ray Cooke for providing advice on English-language wording. This work was supported in part by a grant from the 'Région Aquitaine'. JY Rotge was supported by a PhD grant from the 'Fondation pour la Recherche Médicale'. All behavioral assessment was performed with the Vigiprimate system and the Labwatcher software (Viewpoint) located on the movement platform analysis directed by Dr JR Cazalets, INCIA, CNRS UMR 5287, University of Bordeaux 2.

\section{Author contributions}

JY Rotge: acquisition of data, analysis and interpretation of data; drafting the article; final approval of the version to be published. B Aouizerate: conception and design, acquisition of data, analysis and interpretation of data; drafting the article; final 
approval of the version to be published. V Amestoy: acquisition of data, analysis and interpretation of data; revising the article critically for important intellectual content; final approval of the version to be published. V Lambrecq: acquisition of data, analysis and interpretation of data; revising the article critically for important intellectual content; final approval of the version to be published. $\mathrm{N}$ Langbour: analysis and interpretation of data; revising the article critically for important intellectual content; final approval of the version to be published. Nguyen TH: acquisition of data; revising the article critically for important intellectual content; final approval of the version to be published. S Dovero: acquisition of data; revising the article critically for important intellectual content; final approval of the version to be published. L Cardoit: acquisition of data; revising the article critically for important intellectual content; final approval of the version to be published. J Tignol: analysis and interpretation of data; revising the article critically for important intellectual content; final approval of the version to be published. B Bioulac: analysis and interpretation of data; revising the article critically for important intellectual content; final approval of the version to be published. P Burbaud: conception and design, acquisition of data, analysis and interpretation of data; drafting the article; final approval of the version to be published. D Guehl: conception and design, acquisition of data, analysis and interpretation of data; drafting the article; final approval of the version to be published.

1. Koran LM, Thienemann ML, Davenport R. Quality of life for patients with obsessivecompulsive disorder. Am J Psychiatry 1996; 153: 783-788.

2. Schwartz JM. A role of volition and attention in the generation of new brain circuitry. Toward a neurobiology of mental force. J Consciousness Stud 1999; 6: 115-142.

3. Alptekin K, Degirmenci B, Kivircik B, Durak H, Yemez B, Derebek E et al. Tc-99m HMPAO brain perfusion SPECT in drug-free obsessive-compulsive patients without depression. Psychiat Res 2001; 107: 51-56.

4. Baxter LR Jr, Schwartz JM, Mazziotta JC, Phelps ME, Pahl JJ, Guze BH et al. Cerebral glucose metabolic rates in nondepressed patients with obsessive-compulsive disorder. Am J Psychiatry 1988; 145: 1560-1563.

5. Molina V, Montz R, Martin-Loeches M, Jimenez-Vicioso A, Carreras JL, Rubia FJ. Drug therapy and cerebral perfusion in obsessive-compulsive disorder. J Nucl Med 1995; 36 2234-2238.

6. Perani D, Colombo C, Bressi S, Bonfanti A, Grassi F, Scarone S et al. [18F]FDG PET study in obsessive-compulsive disorder. A clinical/metabolic correlation study after treatment. Br J Psychiatry 1995; 166: 244-250.

7. Swedo SE, Schapiro MB, Grady CL, Cheslow DL, Leonard HL, Kumar A et al. Cerebral glucose metabolism in childhood-onset obsessive-compulsive disorder. Arch Gen Psychiatry 1989; 46: 518-523.

8. Baxter LR Jr, Schwartz JM, Bergman KS, Szuba MP, Guze BH, Mazziotta JC et al. Caudate glucose metabolic rate changes with both drug and behavior therapy for obsessive-compulsive disorder. Arch Gen Psychiatry 1992; 49: 681-689.

9. Lacerda AL, Dalgalarrondo P, Caetano D, Camargo EE, Etchebehere EC, Soares JC. Elevated thalamic and prefrontal regional cerebral blood flow in obsessive-compulsive disorder: a SPECT study. Psychiat Res 2003; 123: 125-134.

10. Saxena S, Brody AL, Ho ML, Alborzian S, Ho MK, Maidment KM et al. Cerebral metabolism in major depression and obsessive-compulsive disorder occurring separately and concurrently. Biol Psychiatry 2001; 50: 159-170.

11. Rotge JY, Dilharreguy B, Aouizerate B, Martin-Guehl C, Guehl D, Jaafari N et al. Inverse relationship between thalamic and orbitofrontal volumes in obsessive-compulsive disorder. Prog Neuropsychopharmacol Biol Psychiatry 2009; 33: 682-687.

12. Chiu CH, Lo YC, Tang HS, Liu IC, Chiang WY, Yeh FC et al. White matter abnormalities of fronto-striato-thalamic circuitry in obsessive-compulsive disorder: a study using diffusion spectrum imaging tractography. Psychiat Res 2011; 192: 176-182.

13. Kang DH, Kim SH, Kim CW, Choi JS, Jang JH, Jung MH et al. Thalamus surface shape deformity in obsessive-compulsive disorder and schizophrenia. Neuroreport 2008; 19: 609-613.

14. Aouizerate B, Cuny E, Bardinet E, Yelnik J, Martin-Guehl C, Rotge JY et al. Distinct striatal targets in treating obsessive-compulsive disorder and major depression. I Neurosurg 2009; 111: 775-779.

15. Aouizerate B, Cuny E, Martin-Guehl C, Guehl D, Amieva H, Benazzouz A et al. Deep brain stimulation of the ventral caudate nucleus in the treatment of obsessive-compulsive disorder and major depression. Case report. J Neurosurg 2004; 101: 682-686.

16. Mallet L, Polosan M, Jaafari N, Baup N, Welter ML, Fontaine D et al. Subthalamic nucleus stimulation in severe obsessive-compulsive disorder. N Engl J Med 2008; 359: 2121-2134.

17. Albin RL, Young AB, Penney JB. The functional anatomy of basal ganglia disorders. Trends Neurosci 1989; 12: 366-375.

18. Haber SN, Calzavara R. The cortico-basal ganglia integrative network: the role of the thalamus. Brain Res Bull 2009; 78: 69-74.

19. Bentivoglio M, Aggleton JP, Mishkin M. The thalamus and memory formation. In: Steriade M, Jones EG, McCormick DA (eds) Thalamus. Elsevier: Oxford, 1997. pp 689-720.

20. Cummings JL. Frontal-subcortical circuits and human behavior. Arch Neurol 1993; 50: 873-880.
21. Aouizerate B, Guehl D, Cuny E, Rougier A, Bioulac B, Tignol J et al. Pathophysiology of obsessive-compulsive disorder: a necessary link between phenomenology, neuropsychology, imagery and physiology. Prog Neurobiol 2004; 72: 195-221.

22. Bush G, Luu P, Posner Ml. Cognitive and emotional influences in anterior cingulate cortex. Trends Cogn Sci 2000; 4: 215-222.

23. Devinsky O, Morrell MJ, Vogt BA. Contributions of anterior cingulate cortex to behaviour. Brain 1995; 118(Part 1): 279-306.

24. Krawczyk DC. Contributions of the prefrontal cortex to the neural basis of human decision making. Neurosci Biobehav Rev 2002; 26: 631-664.

25. Michelet T, Bioulac B, Guehl D, Escola L, Burbaud P. Impact of commitment on performance evaluation in the rostral cingulate motor area. J Neurosci 2007; 27: 7482-7489.

26. Szabo J, Cowan WM. A stereotaxic atlas of the brain of the cynomolgus monkey (Macaca fascicularis). J Comp Neurol 1984; 222: 265-300.

27. Matsumoto N, Minamimoto T, Graybiel AM, Kimura M. Neurons in the thalamic CM-Pf complex supply striatal neurons with information about behaviorally significant sensory events. J Neurophysiol 2001; 85: 960-976.

28. Macia F, Escola L, Guehl D, Michelet T, Bioulac B, Burbaud P. Neuronal activity in the monkey motor thalamus during bicuculline-induced dystonia. Eur J Neurosci 2002; 15: 1353-1362.

29. Edwards MJ, Lang AE, Bhatia KP. Stereotypies: a critical appraisal and suggestion of a clinically useful definition. Mov Disord 2012; 27: 179-185.

30. Jankovic J. Stereotypies. In: Marsden CD, Fahn S (eds). Movement Disorders. 3rd edn. Butterworth-Heineman: Oxford, 1994, pp 503-517.

31. Grabli D, McCairn K, Hirsch EC, Agid Y, Feger J, Francois C et al. Behavioural disorders induced by external globus pallidus dysfunction in primates: I. Behavioural study. Brain 2004; 127(Part 9): 2039-2054.

32. Worbe Y, Baup N, Grabli D, Chaigneau M, Mounayar S, McCairn K et al. Behavioral and movement disorders induced by local inhibitory dysfunction in primate striatum. Cereb Cortex 2009; 19: 1844-1856.

33. Deniau JM, Mailly P, Maurice N, Charpier S. The pars reticulata of the substantia nigra: a window to basal ganglia output. Prog Brain Res 2007; 160: 151-172.

34. Francois C, Grabli D, McCairn K, Jan C, Karachi C, Hirsch EC et al. Behavioural disorders induced by external globus pallidus dysfunction in primates II. Anatomical study. Brain 2004; 127(Part 9): 2055-2070.

35. Francois C, Yelnik J, Percheron G, Fenelon G. Topographic distribution of the axonal endings from the sensorimotor and associative striatum in the macaque pallidum and substantia nigra. Exp Brain Res 1994; 102: 305-318.

36. Sommer MA. The role of the thalamus in motor control. Curr Opin Neurobiol 2003; 13: 663-670.

37. Garner JP. Stereotypies and other abnormal repetitive behaviors: potential impact on validity, reliability, and replicability of scientific outcomes. ILAR J 2005; 46: 106-117.

38. Hugo C, Seier J, Mdhluli C, Daniels W, Harvey BH, Du Toit D et al. Fluoxetine decreases stereotypic behavior in primates. Prog Neuropsychopharmacol Biol Psychiatry 2003; 27: 639-643.

39. Aggleton JP, Burton MJ, Passingham RE. Cortical and subcortical afferents to the amygdala of the rhesus monkey (Macaca mulatta). Brain Res 1980; 190: 347-368.

40. Baxter MG, Murray EA. The amygdala and reward. Nat Rev Neurosci 2002; 3: 563-573.

41. Paus T. Primate anterior cingulate cortex: where motor control, drive and cognition interface. Nat Rev Neurosci 2001; 2: 417-424.

42. Melcher T, Falkai $\mathrm{P}$, Gruber O. Functional brain abnormalities in psychiatric disorders: neural mechanisms to detect and resolve cognitive conflict and interference. Brain Res Rev 2008; 59: 96-124.

43. Schlosser RG, Wagner G, Schachtzabel C, Peikert G, Koch K, Reichenbach JR et al. Fronto-cingulate effective connectivity in obsessive compulsive disorder: a study with fMRI and dynamic causal modeling. Hum Brain Mapp 2010; 31: 1834-1850.

44. Krettek JE, Price JL. Projections from the amygdaloid complex to the cerebral cortex and thalamus in the rat and cat. J Comp Neurol 1977; 172: 687-722.

45. van Vulpen EH, Verwer RW. Organization of projections from the mediodorsal nucleus of the thalamus to the basolateral complex of the amygdala in the rat. Brain Res 1989; 500: 389-394.

46. Davis M. Neurobiology of fear responses: the role of the amygdala. J Neuropsychiatry Clin Neurosci 1997; 9: 382-402.

47. Gritti I, Mariotti M, Mancia M. GABAergic and cholinergic basal forebrain and preopticanterior hypothalamic projections to the mediodorsal nucleus of the thalamus in the cat Neuroscience 1998; 85: 149-178.

48. Hreib KK, Rosene DL, Moss MB. Basal forebrain efferents to the medial dorsal thalamic nucleus in the rhesus monkey. J Comp Neurol 1988; 277: 365-390.

49. Velayos JL, Reinoso-Suarez F. Prosencephalic afferents to the mediodorsal thalamic nucleus. J Comp Neurol 1985; 242: 161-181.

50. Benarroch EE, Stotz-Potter EH. Dysautonomia in fatal familial insomnia as an indicator of the potential role of the thalamus in autonomic control. Brain Pathol 1998; 8: 527-530.

51. Krettek JE, Price JL. The cortical projections of the mediodorsal nucleus and adjacent thalamic nuclei in the rat. J Comp Neurol 1977; 171: 157-191.

52. Aouizerate B, Rotge JY, Bioulac B, Tignol J. (Present contribution of neurosciences to a new clinical reading of obsessive-compulsive disorder). Encephale 2007; 33: 203-210; Epub 2007/08/07. Apport actuel des neurosciences a travers une nouvelle lecture clinique du trouble obsessionnel compulsif. 
53. Jurgens U. The role of the periaqueductal grey in vocal behaviour. Behav Brain Res 1994; 62: $107-117$.

54. Jankovic J. Tourette's syndrome. N Engl J Med 2001; 345: 1184-1192.

55. Leckman JF, Riddle MA. Tourette's syndrome: when habit-forming systems form habits of their own? Neuron 2000; 28: 349-354.

56. Swain JE, Scahill L, Lombroso PJ, King RA, Leckman JF. Tourette syndrome and tic disorders: a decade of progress. J Am Acad Child Adolesc Psychiatry 2007; 46 947-968.

57. Worbe Y, Mallet L, Golmard JL, Behar C, Durif F, Jalenques I et al. Repetitive behaviours in patients with Gilles de la Tourette syndrome: tics, compulsions, or both? PLoS One 2010; 5: e12959.

58. Churchill L, Zahm DS, Duffy P, Kalivas PW. The mediodorsal nucleus of the thalamus in rats-II. Behavioral and neurochemical effects of GABA agonists. Neuroscience 1996; 70 : 103-112.

59. Young KA, Hicks PB, Randall PK, Wilcox RE. Behavioral and frontal cortical metabolic effects of apomorphine and muscimol microinjections into the mediodorsal thalamic nucleus. J Neural Transm Gen Sect 1994; 98: 119-132.

60. Procyk E, Tanaka YL, Joseph JP. Anterior cingulate activity during routine and non-routine sequential behaviors in macaques. Nat Neurosci 2000; 3: 502-508.
61. Dorval AD, Kuncel AM, Birdno MJ, Turner DA, Grill WM. Deep brain stimulation alleviates parkinsonian bradykinesia by regularizing pallidal activity. J Neurophysiol 2010; 104: 911-921.

62. Hammond C, Ammari R, Bioulac B, Garcia L. Latest view on the mechanism of action of deep brain stimulation. Mov Disord 2008; 23: 2111-2121.

63. Lee KH, Hitti FL, Chang SY, Lee DC, Roberts DW, Mclntyre CC et al. High frequency stimulation abolishes thalamic network oscillations: an electrophysiological and computational analysis. J Neural Eng 2011; 8: 046001.

64. Welter ML, Mallet L, Houeto JL, Karachi C, Czernecki V, Cornu P et al. Internal pallidal and thalamic stimulation in patients with Tourette syndrome. Arch Neurol 2008; 65: 952-957.

65. Wichmann T, Delong MR. Deep-brain stimulation for basal ganglia disorders. Basal Ganglia 2011; 1: 65-77.

Translational Psychiatry is an open-access journal published by Nature Publishing Group. This work is licensed under the Creative Commons Attribution-NonCommercial-No Derivative Works 3.0 Unported License. To view a copy of this license, visit http://creativecommons.org/licenses/by-nc-nd/3.0/

Supplementary Information accompanies the paper on the Translational Psychiatry website (http://www.nature.com/tp) 